\section{Diabetic Ketoacidosis in Undiagnosed Acromegaly: A Case Report and Literature Review}

Fabian Delgado, M.D., FACP' ${ }^{1}$, Adrian Valverde ${ }^{2}$, Richard G. Vaca, M.D. ${ }^{3}$

'Vantage Healthcare, Canton, MA

${ }^{2}$ Universidad de Guayaquil, School of Medicine, Guayaquil, Ecuador ${ }^{3}$ Universidad Católica de Santiago de Guayaquil, School of Medicine, Guayaquil, Ecuador

Received Sept. 24, 2021; Accepted for publication Nov. 29, 2021; Published online Feb. 9,2022 https: doi.org 10.17161 lijm.voll5.15881

\section{INTRODUCTION}

Diabetic ketoacidosis (DKA) is both a potentially deadly hyperglycemic crisis and one of the most common causes of diabetes-related hospitalization in the U.S. ${ }^{1,2}$ DKA currently is not established as a complication of acromegaly, ${ }^{3-5}$ even though many authors have described their association. ${ }^{6,7}$ This case reports a middle-aged male patient with a long history of untreated acromegaly who developed DKA.

Acromegaly is a rare endocrinologic disease first mentioned in 1886 by Perrier Marie, characterized by overproduction of growth hormone (GH), and in most cases from a pituitary adenoma. ${ }^{89}$ It often is diagnosed between 40 and 50 years old, ${ }^{10}$ and the common manifestations are acral growth, facial features deformities, soft tissue edema, hyperhidrosis, visual impairment, menstrual disturbances in women, and decreased libido in men. ${ }^{11,12}$

Diabetes mellitus (DM) is a common complication of acromegaly, with a prevalence ranging from $19-56 \%{ }^{3,13}$ The primary mechanism of DM in acromegaly is growth hormone (GH)-induced insulin resistance, ${ }^{14}$ thus hyperosmolar hyperglycemic state (HHS) would be expected as in Type 2 DM complications, instead of DKA. ${ }^{15}$

\section{CASE REPORT}

A 4l-year-old male presented with a two-week history of polyuria, polydipsia, blurred vision, and dizziness, which progressed to nausea and vomiting for the prior two days. He had a medical history of hypertension, and a family history of Type 2 diabetes mellitus in his mother.

Physical examination was remarkable for a body mass index of 30 $\mathrm{kg} / \mathrm{m}^{2}$, blood pressure of $92 / 50 \mathrm{mmHg}$, heart rate of 105 beats $/ \mathrm{min}$, dry mucous membranes, a fruity odor to his breath, and physical findings suggestive of acromegaly: coarse facial features, enlarged mandible, enlarged-fleshy nose, increased space between the lower incisors, and bony overgrowth of the hands (Figure 1).

Visual field examination was unremarkable. Initial blood workup showed high anion gap metabolic acidosis ( $\mathrm{pH} 7.27$, bicarbonate $13.2 \mathrm{mEq} / \mathrm{L}$, and anion gap of $25 \mathrm{mEq} / \mathrm{L}$ ), serum glucose $472 \mathrm{mg} / \mathrm{dl}$, glycosylated hemoglobin (HbAlc) $15.2 \%$, ketones present in blood and urine, and serum osmolality $298 \mathrm{mOsm} / \mathrm{kg}$.

Current 2021 British DKA guidelines for treatment, ${ }^{16}$ as well as ADA 2009 latest guidelines for hyperglycemic crisis in adults, ${ }^{17}$ recommended that the initial therapy starts with $0.9 \%$ sodium chloride solution and regular insulin infusion should be initiated at a rate of 0.1 units $/ \mathrm{kg} / \mathrm{h}$. Efforts also should be made to maintain potassium in normal range. Hourly reassessments are needed to maintain blood glucose below 200 $\mathrm{mg} / \mathrm{dL}$ until DKA resolves. This patient responded avidly to therapy

\section{KANSAS JOURNAL of MEDICINE}

and rapidly stabilized with expected ranges of blood glucose, $\mathrm{pH}$, and bicarbonate.

Magnetic resonance imaging (MRI) of the head revealed a sella turcica mass ( $0.82 \times 0.59$ inches) with bilateral cavernous sinus invasion and likely mass effect on the optic chiasm (Figure 2).

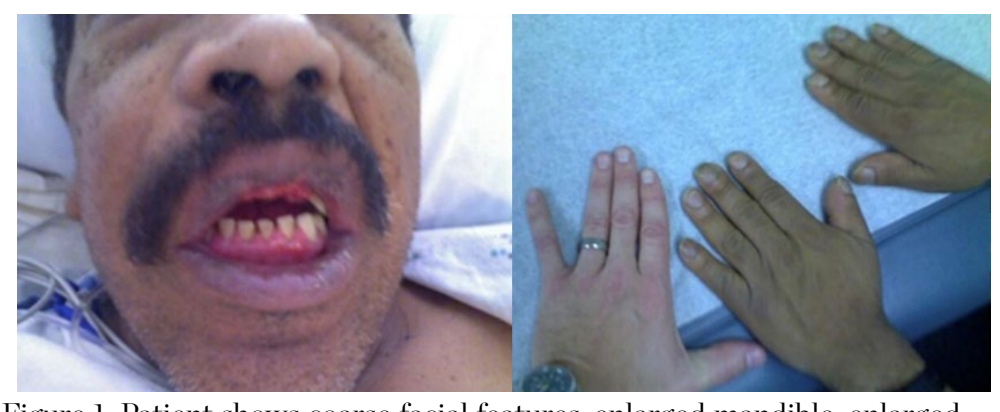

Figure 1. Patient shows coarse facial features, enlarged mandible, enlargedfleshy nose, increased space between the lower incisors (left image), and bony overgrowth of the hands (right image).

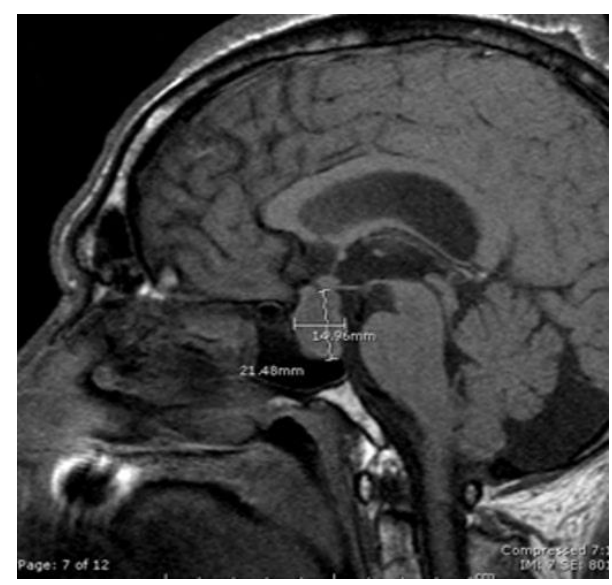

Figure 2. MRI showed a homogeneously enhancing hypointense Tl/isointense T2 mass arising from the sella turcica.

An acromegaly laboratory panel confirmed the disease; random GH level was $98.2 \mathrm{ng} / \mathrm{ml}$ (normal 0-6 ng/ml) and insulin-like growth factor1 (IGF-1) was $398 \mathrm{ng} / \mathrm{ml}$ (normal 101-267 ng/ml). Additional pituitary hormonal testing was unremarkable. A fasting C-peptide was $1.1 \mathrm{ng} / \mathrm{dl}$ (1.1-5 ng/dl), indicating some degree of insulin secretory reserve. Glutamic acid decarboxylase (GAD65) antibodies were negative, ruling out autoimmunity-related diabetes.

The patient underwent trans-nasal, trans-sphenoidal resection of the pituitary mass without complications, and biopsy confirmed pituitary adenoma (Figure 3). 
KANSAS JOURNAL of MEDICINE

DIABETIC KETOACIDOSIS IN ACROMEGALY

continued.

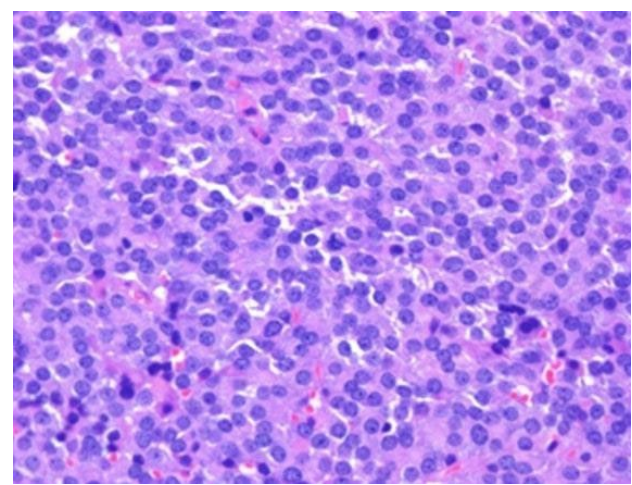

Figure 3. Pituitary adenoma composed of uniform, monomorphic polygonal cells arrayed in cords, with evidence of modest mitotic activity (400X).

Discharged treatment included subcutaneous insulin and metformin. At two-week follow-up, his coarse facial features slightly improved (Figure 4). At two months, the IGF-1 remained elevated at $837 \mathrm{ng} /$ $\mathrm{ml}$ (98-261), indicating residual tumor. The patient was scheduled for a second MRI of the sella and consultation for stereotactic radiation therapy. Unfortunately, the patient was lost to follow-up.

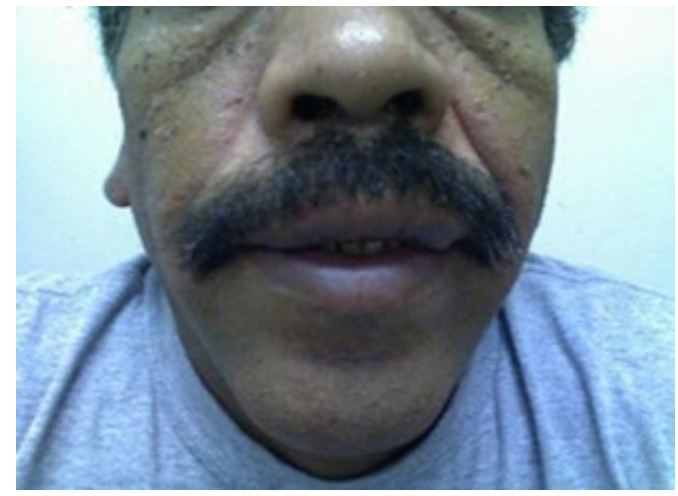

Figure 4. Improvement of coarse facial features two weeks post-surgery.

\section{DISCUSSION}

The DKA episode was the initial presentation of the acromegaly in this patient. It was likely due to a combination of severe insulin resistance from acromegaly and impaired insulin secretion (or relative insulin deficiency) from chronic undiagnosed hyperglycemia. Although there are a few reports of DKA as a complication of acromegaly, ${ }^{6,7}$ the association was not well established.

Diabetes mellitus is a common complication of GH excess and caused by hepatic and peripheral insulin resistance. ${ }^{18}$ At the hepatic level, GH increases gluconeogenesis and glycogenolysis. Peripherally, GH inhibits glycogen synthesis and glucose oxidation. ${ }^{19}$ Growth hormone excess also causes increased lipolysis and, as a consequence, an increase in free fatty acid, which may contribute to insulin resistance. ${ }^{20}$

Diabetic ketoacidosis occurs in the presence of insulin deficiency and excess of counterregulatory hormones like GH. ' The diabetogenic effect of GH initially is compensated by hyperinsulinemia; ${ }^{21}$ if GH excess remains, fasting hyperglycemia may develop, often corresponding with a fall in fasting insulin levels. Finally, the insulin response to carbohydrate exposure is decreased, ${ }^{14}$ which could result in DKA. ${ }^{6,7}$

Islet cells may undergo progressive changes when exposed to prolonged high levels of GH, which could result in cell degeneration, a reduction in insulin production, and finally DKA ${ }^{22}$ However, this mechanism has been borne out only in animal studies. An autopsy from an acromegalic woman who became diabetic and required insulin showed larger and more abundant islets with hypergranular beta cells, ${ }^{23}$ suggesting the initial hyperglycemic state with normal insulin secretion.

Another plausible explanation was that acromegalic patients who develop DKA might have DM independent of their acromegaly. ${ }^{24}$ Two important risk factors for DM secondary to acromegaly are hypertension and a positive family history of $\mathrm{DM} .{ }^{13}$ Both were present in our patient. In these patients, chronic glucose toxicity leads to insulin resistance and contributes to impairment of insulin secretion..$^{25}$

Our patient had characteristics of ketosis prone, antibody-negative diabetes mellitus according to the A $\beta$ classification system, ${ }^{26}$ in which it was hypothesized that chronic hyperglycemia increases susceptibility of the beta cell to desensitization and alters post-insulin receptor signaling. ${ }^{27}$

Endocrine remission occurs in $50 \%$ of GH-secreting macroadenomas after surgery. ${ }^{14}$ Remission was not seen in this patient, owing to the presence of an unresected tumor in his cavernous sinuses. During follow-up, the IGF-1 level remained elevated, reflecting the presence of residual tumor. In previous case reports of DKA in acromegalic patients, complete discontinuation of insulin therapy was possible after GH level normalization. ${ }^{7,24,28}$ In our patient, the clinical scenario indicated that insulin discontinuation would not be possible, presumably due to persistent GH-induced insulin resistance that could yield another DKA episode.

If the patient was not lost to follow-up, further treatment or cure of his acromegaly would have revealed the extent to which his hyperglycemia and DKA were the result of acromegaly.

\section{LIMITATIONS}

Our patient had the phenotype for Type 2 DM, with obesity, age greater than 30 years, and a positive family history. This may have led to an atypical presentation of Type $2 \mathrm{DM}$ rather than acromegaly-related DKA.

\section{CONCLUSIONS}

Growth hormone excess in acromegaly antagonizes insulin action both at the hepatic level and peripherally, making DKA an unlikely complication. It might be caused by B-cell failure due to chronic hyperglycemia. DKA can be managed with positive results, as well as hyperglycemic state after DKA control, until remission of the secretingGH pituitary adenoma. This case report suggested that DKA was a possible complication of acromegaly and that it should be recognized as one.

\section{REFERENCES}

${ }^{1}$ Kim S. Burden of hospitalizations primarily due to uncontrolled diabetes: Implications of inadequate primary health care in the United States. Diabetes Care 2007; 30(5):1281-1282. PMID: 17290038.

2 Dhatariya KK, Vellanki P. Treatment of diabetic ketoacidosis (DKA) hyperglycemic hyperosmolar state (HHS): Novel advances in the management of hyperglycemic crises (UK versus USA). Curr Diab Rep 2017; 17(5):33. PMID: 28364357. 
3 Rolla M, Jawiarczyk-Przybyłowska A, Halupczok-Żyła J, et al. Complications and comorbidities of acromegaly - Retrospective study in Polish center. Front Endocrinol 2021; 12:642131. PMID: 33796075.

${ }^{4}$ Melmed S, Casanueva FF, Klibanski A, et al. A consensus on the diagnosis and treatment of acromegaly complications. Pituitary 2013; 16(3):294-302. PMID: 22903574.

5 Vilar L, Vilar CF, Lyra R, Lyra R, Naves LA. Acromegaly: Clinical features at diagnosis. Pituitary2017; 20(1):22-32. PMID: 27812777.

${ }^{6}$ Weiss J, Wood AJ, Zajac JD, Grossmann M, Andrikopoulos S, Ekinci EI. Diabetic ketoacidosis in acromegaly; A rare complication precipitated by corticosteroid use. Diabetes Res Clin Pract 2017; 134:29-37. PMID: 28951345.

7 Katz JR, Edwards R, Khan M, Conway GS. Acromegaly presenting with diabetic ketoacidosis. Postgrad Med J 1996; 72(853):682-683. PMID: 8944212.

8 Melmed S. Medical progress: Acromegaly. N Engl J Med 2006; 355(24):2558-2573. PMID: 17167139.

9 Marie P. Sur deux cas d'acromégalie; hypertrophie singulière non congénitale des extrémités supérieures, inférieures et céphalique. [French] Paris; 1886.

${ }^{10}$ Holdaway IM, Rajasoorya C. Epidemiology of acromegaly. Pituitary 1999: 2(1):29-41. PMID: 11081170.

${ }^{11}$ Ezzat S, Forster MJ, Berchtold P, Redelmeier DA, Boerlin V, Harris AG. Acromegaly. clinical and biochemical features in 500 patients. Medicine (Baltimore) 1994; 73(5):233-240. PMID: 7934807.

${ }^{12}$ Molitch ME. Clinical manifestations of acromegaly. Endocrinol Metab Clin North Am 1992; 21(3):597-614. PMID: 1521514.

${ }^{13}$ Kreze A, Kreze-Spirova E, Mikulecky M. Risk factors for glucose intolerance in active acromegaly. Braz J Med Biol Res 2001; 34(11):1429-1433. PMID: 11668352.

${ }^{14}$ Colao A, Ferone D, Marzullo P, Lombardi G. Systemic complications of acromegaly: Epidemiology, pathogenesis, and management. Endocr Rev 2004; 25(1):102-152. PMID: 14769829.

${ }^{15}$ English P, Williams G. Hyperglycaemic crises and lactic acidosis in diabetes mellitus. Postgrad Med J 2004; 80(943):253-261. PMID: 15138313.

${ }^{16}$ JBDS-IP Joint British Diabetes Societies for Inpatient Care. The Management of Diabetic Ketoacidosis in Adults. Revised June 2021. https:// abcd.care/sites/abcd.care/files/site_uploads/JBDS_02\%20_DKA_Guideline_amended_v2_June_202l.pdf. Accessed November 8.2021.

17 Kitabchi AE, Umpierrez GE, Miles JM, Fisher JN. Hyperglycemic crises in adult patients with diabetes. Diabetes Care 2009; 32(7):1335-1343. PMID: 19564476.

${ }^{18}$ Holt RIG, Simpson HL, Sönksen PH. The role of the growth hormoneinsulin-like growth factor axis in glucose homeostasis. Diabet Med J Br Diabet Assoc 2003; 20(1):3-15. PMID: 12519314.

19 Møller N, Gjedsted J, Gormsen L, Fuglsang J, Djurhuus C. Effects of growth hormone on lipid metabolism in humans. Growth Horm IGF Res 2003; 13(Suppl A):S18-S21. PMID: 12914720.

${ }^{20}$ Kaiser N, Leibowitz G, Nesher R. Glucotoxicity and beta-cell failure in type 2 diabetes mellitus. J Pediatr Endocrinol Metab 2003; 16(1):5-22. PMID: 12585335.

${ }^{21}$ Luft R, Cerasi E, Hamberger CA. Studies on the pathogenesis of diabetes in acromegaly. Acta Endocrinol (Copenh) 1967; 56(4):593-607. PMID: 5630505.

${ }^{22}$ Pierluissi J, Campbell J. Metasomatotrophic diabetes and its induction: Basal insulin secretion and insulin release responses to glucose, glucagon, arginine and meals. Diabetologia 1980; 18(3):223-228. PMID: 6989696.

${ }^{23}$ CLINICO-PATHOLOGIC conference; acromegaly, diabetes, hypermetabolism, proteinuria and heart failure. Am J Med 1956; 20(1):133-144. PMID: 13282930.

${ }^{24}$ Kopff B, Mucha S, Wolffenbuttel BH, Drzewoski J. Diabetic ketoacidosis in a patient with acromegaly. Med Sci Monit 2001; 7(1):142-147. PMID: 11208511.

${ }^{25}$ Rossetti L, Giaccari A, DeFronzo RA. Glucose toxicity. Diabetes Care 1990; 13(6):610-630. PMID: 2192847.

${ }^{26}$ Balasubramanyam A, Nalini R, Hampe CS, Maldonado M. Syndromes of ketosis-prone diabetes mellitus. Endocr Rev 2008; 29(3):292-302. PMID: 18292467.

${ }^{27}$ Umpierrez GE, Casals MM, Gebhart SP, Mixon PS, Clark WS, Phillips LS. Diabetic ketoacidosis in obese African-Americans. Diabetes 1995; 44(7):790-795. PMID: 7789647.

28 Westphal SA. Concurrent diagnosis of acromegaly and diabetic ketoacidosis. Endocr Pract 2000; 6(6):450-452. PMID: 11155217. 